\title{
LUDWIG'S ANGINA AND ANAESTHETIC DIFFICULTIES: A CASE REPORT
}

\author{
Sarda Devi Kangabam¹, Ibemhal Heisnam²
}

\section{HOW TO CITE THIS ARTICLE:}

Sarda Devi Kangabam, Ibemhal Heisnam. "Ludwig's Angina and Anaesthetic Difficulties: A Case Report". Journal of Evolution of Medical and Dental Sciences 2015; Vol. 4, Issue 28, April 06; Page: 4916-4919,

DOI: $10.14260 /$ jemds $/ 2015 / 716$

INTRODUCTION: Patients with deep neck infections present challenging airways for an anesthesiologist. Ludwig's angina is potentially lethal, rapidly spreading cellulitis involving the floor of the mouth and neck. Without aggressive management it often results in life threatening upper airway obstruction. Securing the airway remains the top priority in treatment of Ludwig's angina. Although awake fibreoptic intubation remains the ideal method for securing the airway, but it is not available in every set up, so all feasible options of securing the airway should be prepared. We present a case successfully managed at our hospital with a brief review of airway management options.

KEYWORDS: Ludwig's angina, airway, intubation.

CASE REPORT: A 32 years old man weighing $60 \mathrm{~kg}$ was admitted in emergency ward with complaints of pain and swelling in the mouth and neck and difficulty in opening the mouth for 4 days. He had fever with rigor but no breathing difficulty. There was history of recent tooth ache which was not attended properly. He was diagnosed as a case of Ludwig's angina and posted for emergency drainage.

On examination, he had a diffuse, tender swelling in the sub mental and submandibular area limiting the mouth opening but without respiratory distress. He was febrile $\left(101^{\circ} \mathrm{F}\right)$, with a pulse rate of $120 / \mathrm{min}$, blood pressure was $130 / 90 \mathrm{mmHg}$, respiratory rate of $24 / \mathrm{min}$. and oxygen saturation $\left(\mathrm{SpO}_{2}\right)$ was $94 \%$. Airway examination showed restricted mouth opening with inter incisor gap of $2 \mathrm{~cm}$ ( $<3$ finger breath), Mallampati grade 3 and thyromental distance of about $4 \mathrm{~cm}$. He was not able to protrude his lower incisors to reach the upper incisors.

Intravenous line was started with ringer lactate, and antibiotics ceftriazone and metronidazole were started. Paracetamol injection was given intramuscularly. Difficult airway was expected, so possible options for intubation available in our hospital were prepared prior to induction. This includes bougie, flexi tip laryngoscope blades along with two normal blades (size no 3 \& 4), nasal airway and different sizes endotracheal tubes (6. 5, 7. 5, 8. $0 \mathrm{~mm} \mathrm{I}$. D). Under size tubes were also kept since subglottic edema was expected. A tracheostomy set was also kept ready.

The patient was premedicated with intravenous tramadol $100 \mathrm{mg}$ and ondansetron 8mg. Pulse, BP, ECG \& $\mathrm{SpO}_{2}$ were monitored prior to induction. The patient was pre-oxygenated for about 3 minutes and gradual gas induction with sevoflurane was done. Laryngoscopic assessment was done and vocal cord was partially visualized. $50 \mathrm{mg}$ of propofol was added to deepen the anaesthesia. Laryngoscopy was performed and intubation done with the help of bougie. First $8.0 \mathrm{~mm}$ (I. D) endotracheal tube was threaded over the bougie but could not negotiate the laryngeal inlet, so $7.0 \mathrm{~mm}$ (I. D) tube was used. Tracheal placement of tube was confirmed by auscultation and appearance of $\mathrm{ETCO}_{2}$ in the monitor. Atracurium $25 \mathrm{mg}$ and dexamethasone $8 \mathrm{mg}$ were given. Anaesthesia was continued with nitrous oxide in oxygen mixture and sevoflurane with closed circuit and intermittent 


\section{CASE REPORT}

positive pressure ventilation. Intra-operatively the vitals were stable. Incision and drainage were performed and a drain left behind. After the end of the procedure residual neuromuscular blockade was antagonized with neostigmine $(2.5 \mathrm{mg})$ and glycopyrrolate $(0.4 \mathrm{mg})$. Post-operative vitals were stable with a pulse rate of $90 / \mathrm{min}$., blood pressure of $130 / 80 \mathrm{mmHg}$ and oxygen saturation of $98 \%$. The patient was shifted to recovery room. An emergency intubation tray was kept near his bed. Next day he was shifted to general ward and was discharged after 7 days.

DISCUSSION: Ludwig's angina otherwise known as "angina ludovici" is rapidly progressive, potentially fulminant cellulitis involving the sublingual, submental and submandibular spaces and typically originates from an infected or recently extracted tooth, most commonly the lower second and third molars. ${ }^{1}$ Ian M. Furst, Peter Ersil, Marco Caminiti, in their study, reported Ludwig's angina and mediastinitis as a complication of tooth abscess. ${ }^{2}$ It leads to dysphagia, odynophagia and woody edema in the sublingual region, forcing the tongue up and back with the potential for airway obstruction. Oral or dental infections are implicated in up to $70 \%$ of cases. Poor dental hygiene, gingivitis and periapical abscesses are commonly involved in the pathogenesis with streptococcus viridans and staphylococcus aureus being the main organism. ${ }^{3}$

The most common presentation of Ludwig's angina is pain and trismus along with fever and dysphagia. Breathing difficulty, stridor and cyanosis are late signs of impending airway obstruction. The most serious complication of an untreated or severe case is asphyxia caused by expanding edema of soft tissues of the neck. ${ }^{3}$ Another common cause of death is acute loss of airway during interventions. Other complications which may occur are spread of infection to the mediastinum, carotid sheath, skull base, and meninges. The mortality rate from these invasive infections can be as high as $50 \% .^{1}$ Because of its invasive nature, early recognition and treatment is extremely important. In the pre-antibiotic era a mortality of $54 \%$ was reported but now it vary between $0-8.5 \%$ only. Modern dental care and use of good antibiotics for oral infections have made Ludwig's angina rare. Treatment involves appropriate antibiotics, monitoring and protection of the airway in severe case and where appropriate, urgent maxillo- facial surgery or dental consultation to incise and drain the collection. ${ }^{4}$

Patients with deep neck infections present challenging airways for an anesthesiologist. These infectious processes are not common but, untreated, may progress rapidly to airway obstruction that could be lethal. Prompt airway management is critical, but the presence of swelling of the neck, glottic edema, elevation of the tongue, trismus, or pharyngeal edema create formidable problems. In this patient, restricted mouth opening was contributed by muscular spasm due to pain, in addition to the edema of the floor of mouth. So after gas induction and propofol administration, spasm was relieved and direct laryngoscopic assessment could be done. In early stage of the disease general anaesthesia may overcome trismus and allow the mouth to be opened for rigid laryngoscopy. ${ }^{5} \mathrm{An}$ under-size tube was used because of the prevailing airway edema. We avoided the use of any neuromuscular blocking agent before securing the airway. Intravenous dexamethasone was given to reduce airway edema.

Blind nasal technique for intubation is preferred if mouth opening is restricted or absent, however it is better to avoid in Ludwig's angina as it may cause bleeding, laryngospasm and airway edema. Complete airway obstruction could be precipitated, necessitating an emergency tracheostomy. Orotracheal intubation is also difficult because of distorted airway anatomy, tissue immobility, and limited access to the mouth. 
Elective awake tracheostomy has been suggested for all patients with deep neck infections; however there may be good reasons to avoid tracheostomy. Cellulitis of the neck with involvement of the tracheostomy site makes it a more difficult procedure. Moreover, surgical dissection of the fascial planes in the neck may actually open and contaminate the pathways, leading to life threatening mediastinal invasion. Tracheostomy also conveys substantial risk of infection spread to mediastinum and tracheal stenosis as a late complication. More recent reviews of anaesthesia management report good results without the use of tracheostomy. 6,7

Awake fibreoptic intubation has been recommended for airway management in patients with a compromised airway. ${ }^{6}$ Distorted anatomy, airway edema and secretions may pose difficulty in performing fibreoptic intubation in Ludwig's angina. But in experienced hands it can be performed safely. The first successful fibreoptic nasotracheal intubation in a patient with Ludwig's angina was reported in 1974; however subsequent reports were associated with frequent failure. But that was attributed to inadequate preparation of the patient and lack of experience. But now with good expertise and proper preparation the success rate has increased and is the preferred method. ${ }^{7}$ Tracheostomy using local anaesthesia is recommended when such facility is not available or intubation attempts have failed. However advanced cases may pose problems because of anatomical distortion of the anterior neck. The choice of airway maneuvers must be individualized depending on the severity of the disease, and experience of the attending physician. ${ }^{8}$

\section{REFERENCES:}

1. Durand M Joseph M: Infections of the upper respiratory tract. In Harrison's Principles of International Medicine, Volume 1. 16 $6^{\text {th }}$ edition Edited by: Braunwald E, Fauci AS, Kasper DL, Braunwald E, Mauser S, Longo D, Jameson JL New York: McGraw-Hill; 2001: 191.

2. Ian M. Furst, Peter Ersil, Marco Caminiti: A rare complication of tooth abscess - Ludwig's Angina and Mediastinitis. J Can Dent Assoc 2001; 67: 324-7.

3. Moreland LW, Corey J, McKenzie R: Ludwig's Angina, Report of a case and review of the literature. Arch Intern Med. 1988 Feb; 148 (2): 461-6.

4. Mohd Razif Mohd Yunus, Fadzlina Abdul Karim, SHA Primuharsa Putra, Roslan Abdul Rahman, Heng Swee Heong et al: Ludwig's Angina; A Retrospective study of seven cases. Asian J Oral Maxillofac Surg. 2006; 18: 263-267.

5. Loughnan TE, Allen DE: Ludwig's angina. The anaesthetic management of nine cases. Anaesthesia. 1985 Mar; 40 (3): 295-7.

6. Anand H Kulkarni, Swarupa D Pai, Basant Bhattarai, Sumesh T Rao, and M Ambareesha: Ludwig's angina and airway considerations: A case report. Cases Journal 2008, 1: 19.

7. Andranik Ovassapian, Meltem Tuncbilek, Erik K. Weitzel, Chandrashekhar W. Joshi: Airway management in adult patients with deep neck infections: A case series and review of the literature. Anesth Analg 2005; 100: 585-589.

8. Mehrotra, Manish, Mehrotra Sandeep: Decompression of Ludwig's Angina under cervical block. Anesthesiology: Volume 97 (6) Decem 2002 pp 1625-1626. 


\section{CASE REPORT}

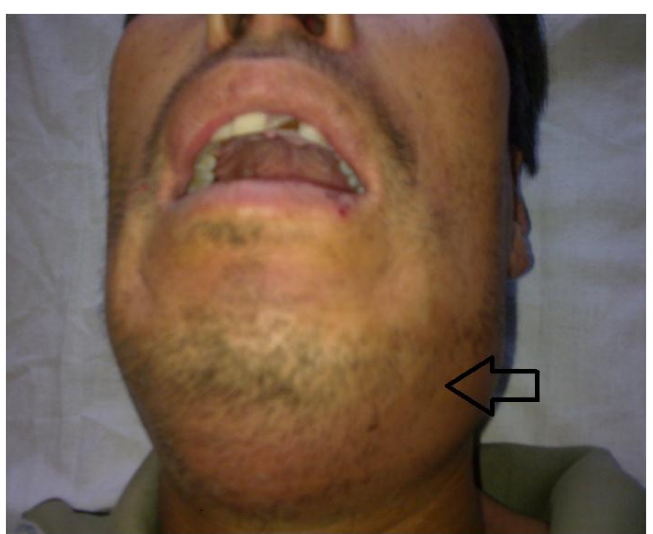

Fig. 1: . Diffuse submental and submandibular swelling (arrow)

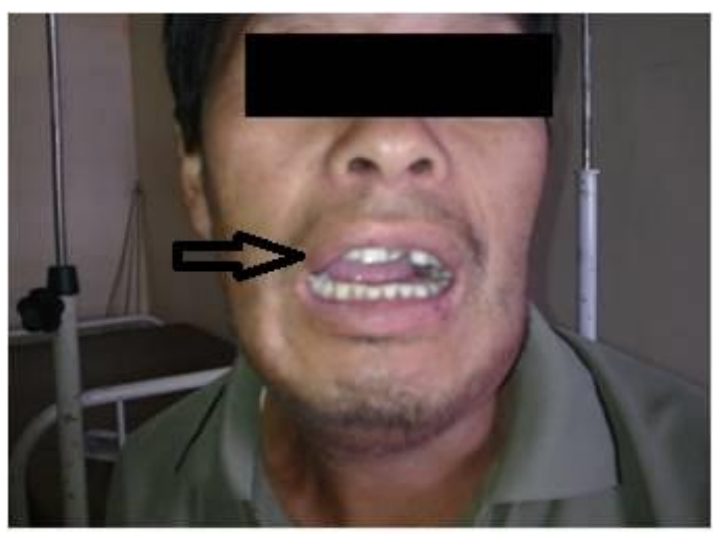

\section{Fig. 2 : Fig 2. Restricted mouth opening (arrow)}

\section{AUTHORS:}

1. Sarda Devi Kangabam

2. Ibemhal Heisnam

\section{PARTICULARS OF CONTRIBUTORS:}

1. Junior Resident, Department of Anaesthesia, JNIMS.

2. Assistant Professor, Department of Anaesthesia, JNIMS.

\section{FINANCIAL OR OTHER} COMPETING INTERESTS: None

\section{NAME ADDRESS EMAIL ID OF THE CORRESPONDING AUTHOR: \\ Dr. Sarda Devi Kangabam, \\ C/O Thangjam Kameshwar Singh, Uripok Sinam Leikai, Near Langol View Clinic, Imphal West-795001, Manipur. \\ E-mail: kangsmuskan@yahoo.co.in}

Date of Submission: 12/03/2015. Date of Peer Review: 13/03/2015. Date of Acceptance: 23/03/2015.

Date of Publishing: 06/04/2015. 